\title{
Analysis and Methods of System Management of Retail Trade City District
}

\author{
Aleksander P. Zhabin ${ }^{1}$ \\ Igor A. Grigoryants 1
}

1. Samara State University of Economics, Russia, 443090, Samara, Sovetskoi Armii Street, 141

2. Samara State University of Economics, Russia, 443090, Samara, Sovetskoi Armii Street, 141 Correspondence: Igor A. Grigoryants, Samara State University of Economics 443090, Russia, Samara; Sovetskoi Armii Street, 141, Email: krater-i@list.ru

\section{Doi:10.5901/mjss.2015.v6n6s3p435}

\section{Abstract}

The article presents data on the current state of retail in Samara city. The authors conclude chaotic development of shopping areas, excluding the real need for them. Based on official statistics of Samara city and relying on federal legislation in this area, the authors suggest methods of calculation of availability of shopping areas for the foreseeable future. The authors analyze the population of Samara, the retail trade turnover in Samara for a few years, socio-economic indicators of living standards, such as minimum wage, the average monthly wage, real wages in percent to the previous period, on the basis of which developed a linear mathematical model. These models allow to predict the change of these indicators for the period ahead. On the basis of these forecasts it is possible to calculate the needs of Samara in the trade area. This will allow you to determine the strategy of development of retail trade of Samara.

Keywords: methodology, algorithm, shopping areas, Samara city, the prediction, model, the object of trade.

\section{Introduction}

\subsection{Introduce the Problem}

Trade is an important component of the economy and has a significant impact on the quality of life of the population.

Trade sector is the final link in the supply chain from producer to consumer. From the efficiency of the organization of trading activity (geographic availability of goods for the population, minimizing the costs of trade, sales process optimization in retail outlets) depends directly on the volume of sales producers. The development of the trade sector determines the proportion of local products in the range of commercial enterprises that directly affect the value of the gross regional product.

At the same time, the trade sector is largely forms the active entrepreneurial class, which is important for the diversification of the economy and its sustainable growth in the long term.

\subsection{Explore Importance of the Problem}

The main problems of trade of Samara at the present stage of development of the market include:

— insufficient effectiveness of state regulation;

- inadequate infrastructure (lack of retail and warehouse facilities, the high cost of buying and renting real estate and land, the high cost of the work to ensure the engineering services, the lack of trade and transport infrastructure in remote areas, weak economic ties between producers and trade organizations, insufficient the level of development cooperation, etc.);

- low qualification and lack of personnel at all levels;

- saturation of retail space;

- lack of attractiveness to business trade development on the outskirts of the city.

So far, the development of retail outlets was carried out chaotically, without regard to retail space and public areas of Samara. There were no predictive models quantify the required amount of retail space and forecasting of the needs for the foreseeable future. All this led to the need to develop predictive models to determine the needs of Samara in the amount of retail space in the long and medium term. 


\subsection{Describe Relevant Scholarship}

Small and medium enterprises play an important role in the economy and employment in foreign countries. Small and medium enterprises usually comprise about $99 \%$ or more of all companies provide about $50 \%$ of the jobs provide a significant share of retail trade turnover.

The potential threat of large retail formats and consolidation of the market is to reduce the share of small and medium-sized businesses in the retail trade. However, international experience shows that the development of networks does not lead to the disappearance of small businesses because small businesses are able to compete due to the higher individualization of services and offers unique marketing or reorientation of other sectors of the economy.

\section{Method}

In order to determine the views of residents of Samara concerning the retail system was conducted marketing research. This study was aimed at determining the following opinion:

— how many suits and enough retail stores in the place of residence of the respondent;

— which of retail stores most visited by respondents;

— whether the respondents are satisfied with the service system of retail stores;

— which of retail outlets and what format is very popular among the respondents;

- whether respondents prefer to visit the retail outlets close to home or being away from home;

- how many of the respondents are satisfied with the quality and breadth of the range of retail outlets of Samara;

- how many of the respondents are satisfied with the price range of retail outlets of Samara;

- how many of the respondents are satisfied with the level of service in retail outlets of Samara.

Under market research meant the systematic collection, display and analysis of data on various aspects of marketing. Marketing research - a feature that connects marketers through information to markets, customers, competitors, with all the elements of the environment marketing.

Of the total population, all the inhabitants of Samara at the age of 18 years of this study sample was 447 people, the $95 \%$ confidence level, were involved in all areas of Samara, the study took place between November and December of 2013.

Desk study showed that the overall trend - shift of consumer preferences towards major shopping complexes with a wide range of goods, services and entertainment. His well-deserved priority, the highest position in the qualitative characteristics that determine the attractiveness of shopping malls, take location, accessibility and the provision of sufficient parking space. Objects with poor marketing concept, the problems of accessibility and lack of parking not enjoy great demand. This is essentially a one hypothesis study.

The tendency of buyers to a particular commercial enterprise in the presence of competition depends on the convenience of its location, the breadth and completeness of the range of goods, the level of prices, quality of service and time spent on maintenance in the company, the quality of the provided services - delivery, acceptance of pre-orders, etc. However, there are several disadvantages of secondary data, which are known to every marketer.

It is from these points of view, and it was decided to carry out marketing research of consumer preferences of retail outlets to collect and process basic information and to confirm or refute this hypothesis.

This study was conducted by following all the rules of marketing research. Results of marketing research are reflected in the following charts.

These studies have determined where most residents of Samara make purchases. The result is shown in Figure 1. 


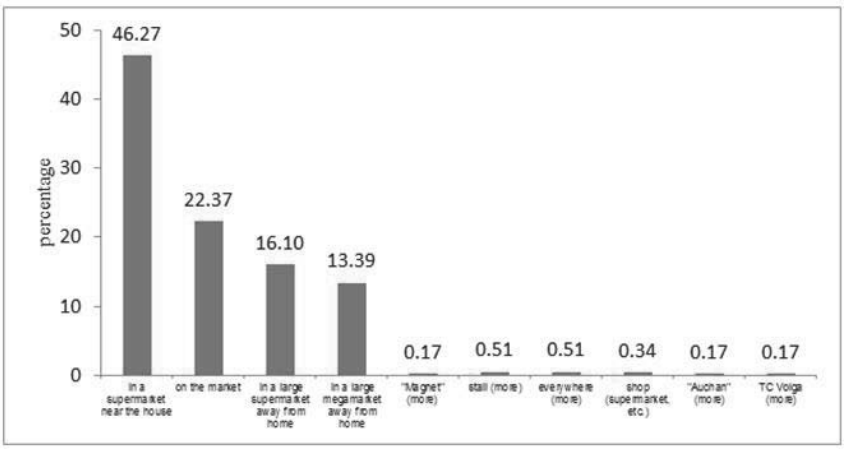

Figure 1. The preferred place to shop

Figure 1 shows that the residents of Samara most prefer to shop close to home by visiting the nearest supermarket. This is confirmed in particular expert opinion described previously that there is a shift of consumer preferences towards shopping centers. However, in this case, as we see it is not exactly shopping centers, namely supermarkets «at home». You can also conclude that the residents make purchases on the market. The market is still the preferred place to shop. Approximately the same position at the supermarket away from home and large megamarket of type Mega. Perhaps in the near future interests of the citizens redistributed towards megamall on the outskirts of the city.

However, while shopping city residents prefer to return on foot. This reflects the Figure 2, confirming the data presented in Figure 1.

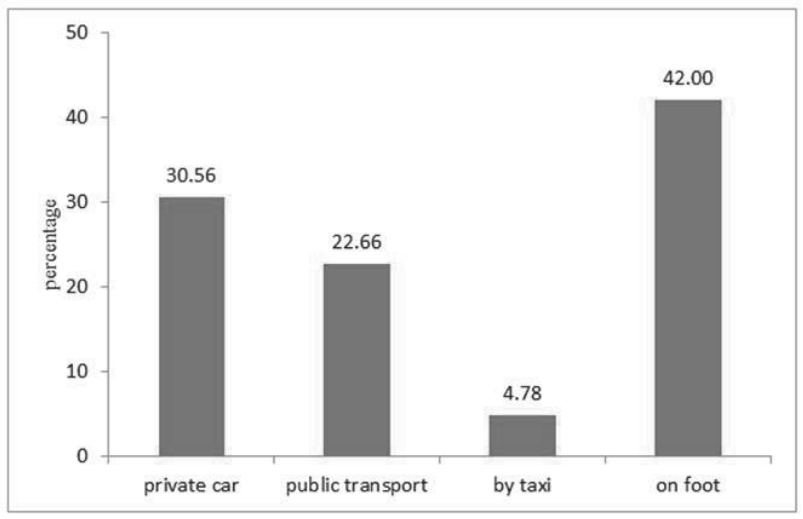

Figure 2. Preferences in the delivery of goods to the house

As seen in Figure 2, most residents prefer to get to the house, shopping on foot. However, there is not a small part of the citizens to get to the house by car. It may be those who commit the purchase of the house returning from work, as well as those who may be making purchases at home easily change it to make purchases away from home, because personal transport it allows them to do so. Also to be considered are those who prefer to return home with their purchases using public transport, and those who make purchases at a distance from the house and a small group of $5 \%$ of those who use taxis. Thus, approximately $59 \%$ of the sample are potential buyers have all the possibilities to move to make purchases away from home, and this trade cents, or megamall on the outskirts of the city. They can make the shift accents another problem of the retail trade of Samara, which is necessary to pay close attention of the authorities - is the level of service in retail stores (Fig. 3). 


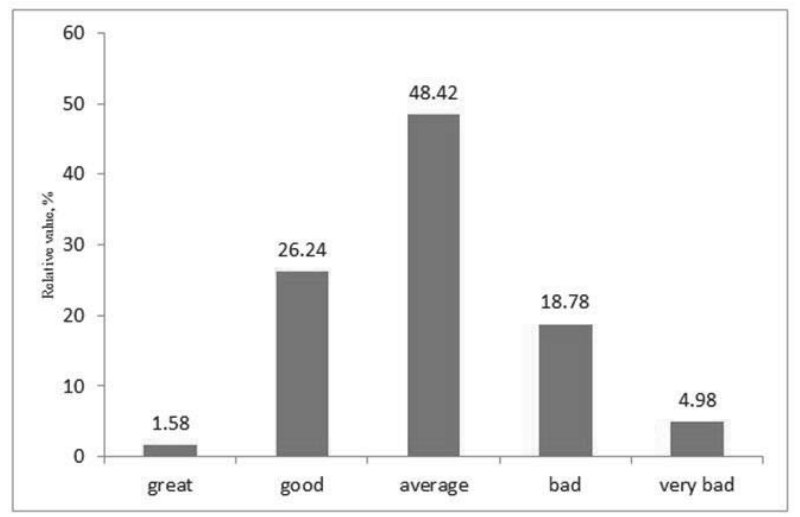

Figure 3. The level of service in retail stores

In Figure 3, you need to pay close attention to negative values the horizontal axis. Most residents spoke about the level of care as the average, so you can add here the bad service and very bad. Total amount of the negative range is $73 \%$ as opposed to positive values, where the sum is equal to $28 \%$. It can be concluded that own commercial networks, retail outlets do not pay close attention to the area of customer service, which is particularly important for companies that combine the provision of goods and services at the same time. In this case it is advisable to develop various training programs of various levels.

It is not enough are important factors, the most important for the citizens in the selection of retail outlet (see Fig. 4)

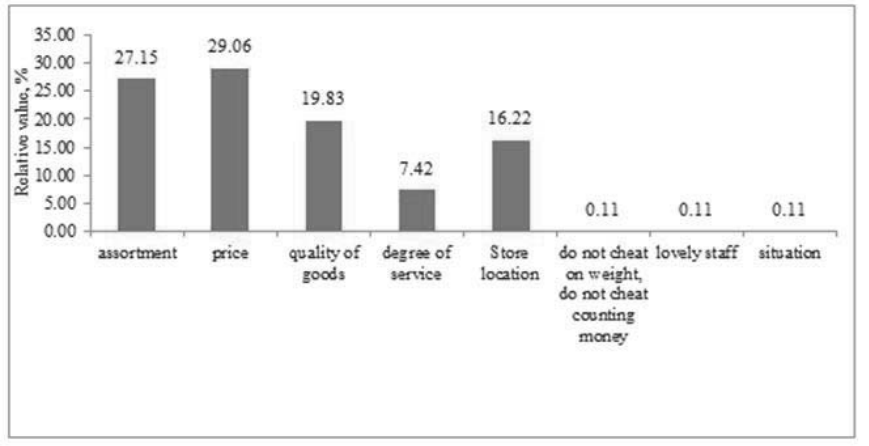

Figure 4. Most important factors when choosing a retail outlet

As can be seen from Figure 4 the most attention and the requirement of Samara residents impose a price range and a variety of quality products. There also should pay attention to the fact that not a few important for the residents of the city is the location of the store. With geographic portal of Samara on interactive map you can see unreached areas in contrast to quite severe competition in other parts of the city. This was discussed in the last chapter of this work.

Sufficient attention should be given to the opinion of the inhabitants of the city as a range of products presented in retail outlets (Fig. 5) 


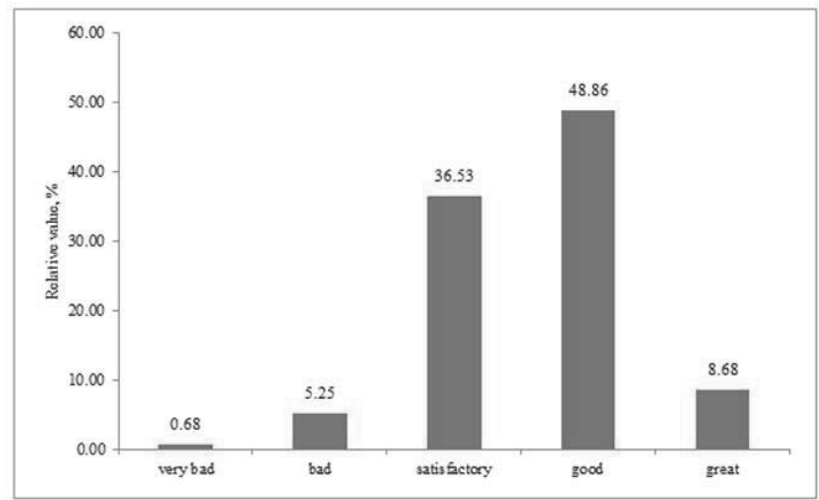

Figure 5. Assessment of the quality range of retail stores

In general, as shown in Figure 5, residents assess the quality of the range of goods as good. However, the situation is problematic is the fact that on average, a difference of opinion between the good and the middle and lower-middle-range quality is not great. From the standpoint of the state should pay attention to it.

The opinion of residents about the level of prices was more positive (Fig. 6).

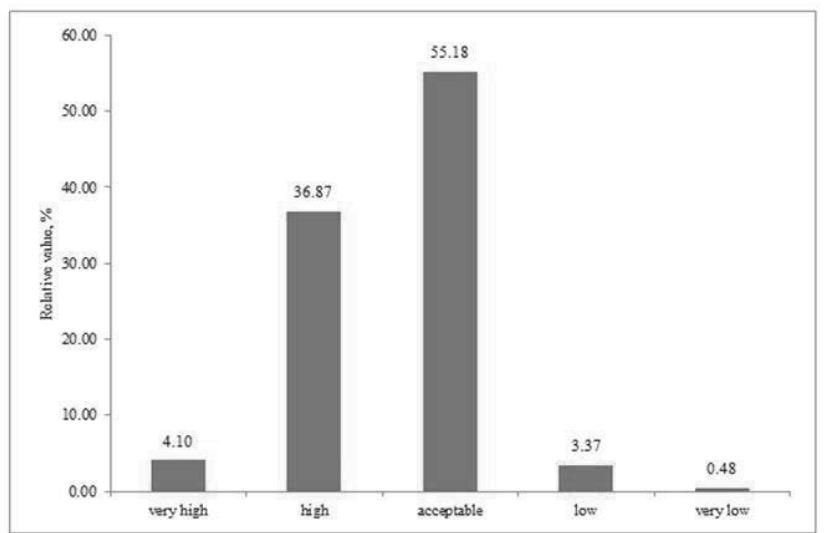

Figure 6. The opinion of the residents of Samara on prices at retail outlets

Figure 6 demonstrates that the level of prices on average residents GO Samara evaluated as acceptable. However, a small fraction of citizens believe the price level high. Taking into account the data presented in Figure 4, it can be concluded that the pricing policy is the most important part in the evaluation of the retail and expedient will constantly analyze the level of prices, conducting correlation analysis as compared to the income of city residents, the rate of inflation, avoiding the process of uncontrolled price increases.

Experts in the field of analytics retailers have long noted the attention of buyers to the place of production, saying that the most demanded consumer goods produced domestically. We analyzed the situation in the retail market of Samara. The results are shown in Figure 7. 


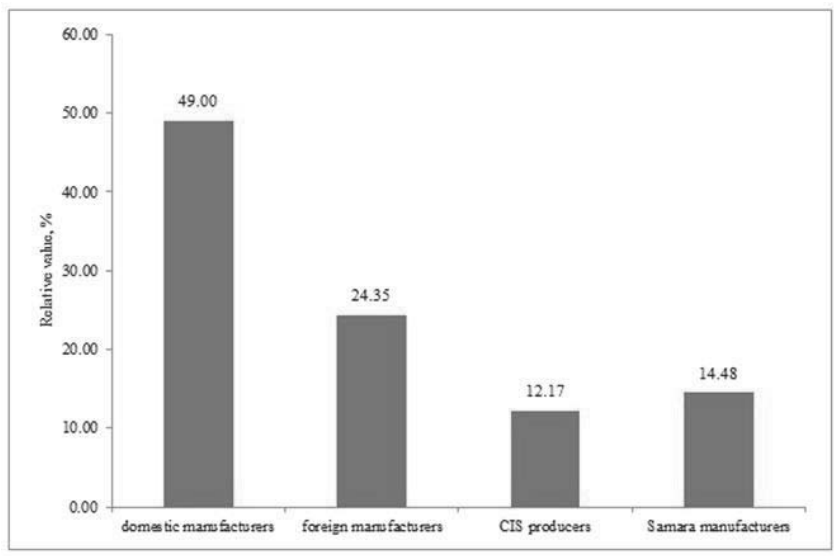

Figure 7. Preferences consumer products inhabitants of Samara.

This figure confirms the opinion of experts and in the city of Samara. Most of all, citizens prefer consumer goods domestic manufacturer. There is a certain percentage of the preferences of the foreign producers. It is worth paying attention to paragraph «Samara manufacturers». Here, the figure reached 14\%. Considering the indicator «domestic producers» in the notion that some of the respondents put the concept of «Samara manufacturer» can make a conclusion that the producers of the Samara region are quite popular and preferred by residents of the provincial capital. This fact demonstrates the need to pay attention on the part of public authorities more targeted development of small business of the Samara region, the development of farming, revival of the family business, the development of private brands. Small and medium-sized producers more likely to have opportunities to sell their products through small retail formats. This distribution can be a single chain of distribution of the goods of small producers. This way of direct trade is one of the most profitable, and therefore the most attractive for the small producer. Since the logistical structure of large retail chains sometimes not easy to work with small producers, small businesses could work directly with small producers. The development of small-scale production will be a powerful step towards the development of rural areas.

\section{Results}

Let formulate the main conclusions of the study of the retail trade in Samara.

Today in the city there is a shortage of quality retail space, under which buyers and retailers will include:

- location - in a densely populated area or not far from the urban traffic arteries and public transportation, having convenient access roads. Today there is a tendency that the buyers 'not linked' to the residence and ready to go for the right products, including by car. Based on this fact, the next index of competitiveness of retail space;

- availability of parking - retailers wishing to open shops in the squares, with convenient parking, as Many buyers prefer to come by car;

- demand area with an entertainment component: Samarians happy to go to the big shopping centers, often with their entire families. After all, among other things where you can relax in the cafe, watch a movie, go bowling and play with your child on the playground. Thus, the presence of such institutions increased client flow not only in the shopping center, but also among retailers located there.

In addition, the retailers themselves worried about the composition of other tenants of retail space, and they tend to be «neighbors» were also interested in customers, it has an indirect influence on the permeability of their outlets.

Today's shopping areas, generally not meet the above requirements. The city high proportion of irrelevant shopping centers, rebuilt from old buildings (for example, those that are in the city center of Lenin and Samara regions).

The above requirements for quality retail space are responsible only new and recently built shopping malls (Park House, Cosmoport, Viva Land, Mega etc.) And modern building that «are adapted» to the conditions of the tenants.

In addition, it should be noted that today there is a competition among retailers: everyone wants to take vacant space. In the city there is a competition among developers for the construction of such facilities.

An important factor for the inhabitants of Samara, the study found, is the location of the store. In this connection it 
is necessary to develop a policy of balanced arrangement of outlets in the city. Accumulation of retail outlets in some parts of the city and their absence in others, creates a nuisance to residents and upsets the balance of competition. However, not every retail formats can be placed in different parts of the different aspect of the city as Samara. And not every retail chain may agree to work in certain parts of the city. In this regard, the question arises about multiformat outlets, and the difference in the ownership of different store formats allows you to develop and manage the competition in this market. This involvement in the trade of products of small and medium producers of the Samara Region, which will help improve the efficiency of the supply chain of distribution of goods, will give the opportunity to enhance medium-sized enterprises, rural producers, the development of ecologically pure product, will ensure price competition, as well as price controls. This control determines the social orientation of the program of development of retail trade in Samara, which provides food assistance to socially vulnerable layers of the population. This issue needs to be addressed, together with other departments of the government of Samara.

It is necessary to draw a clear classification of retail outlets, depending on the tenants, the shopping area of the object, its distance from the potential and actual visitors. However, this work should also be held in conjunction with the department in charge of Samara, the system includes a traffic and transportation urban district. The main factor here is to ensure stability and prevent the transport of traffic jams when you visit a particular shopping center.

The system of retail space is governed by the on September 24, 2010 N 754. This resolution also provides for the use of the regional factor correction. The use and payment of this ratio will enable the next five years, during which the regulations will apply for retail space as provided by this regulation, to determine the minimum necessary security Samara retail space.

You can also note that in the developed countries (Ireland, England, Belgium, Portugal, Italy, France) for the protection of competition introduced quite serious restrictions on the construction of large shopping centers is a license for retail space over a certain size restrictions for the construction product and not product areas, restrictions on work schedules of stores and limit their night work, measures aimed at protecting small business.

The low level of service in retail outlets of the city makes to revise the system of personnel training for various units of trade, significantly enhance the quality control of products sold.

\section{Discussion}

So far, the development of retail outlets was carried out chaotically, without regard to retail space and public areas of Samara. There were no predictive models quantify the required amount of retail space and forecasting of the needs for the foreseeable future. All this led to the need to develop predictive models to determine the needs of Samara in the amount of retail space per dosgosrochny and medium term.

Method of calculation of availability of retail space the city of Samara and Samara regions for 2015 - 2020 years., Proposed by the authors, consists of a calculation algorithm of availability of Samara, the total area of commercial properties.

Later in this article uses data for the calculations are taken from the yearbook «Samara in figures», produced by the Federal State Statistics Service, available from the website of the territorial body of the Federal State Statistics Service of the Samara Region.

Let consider in more detail the first algorithm - an algorithm for calculating the area of availability of commercial facilities in Samara.

To automate the process of calculating the area of availability of commercial facilities developed an algorithm (Fig. 8), implemented on the basis of the program Mathcad. 


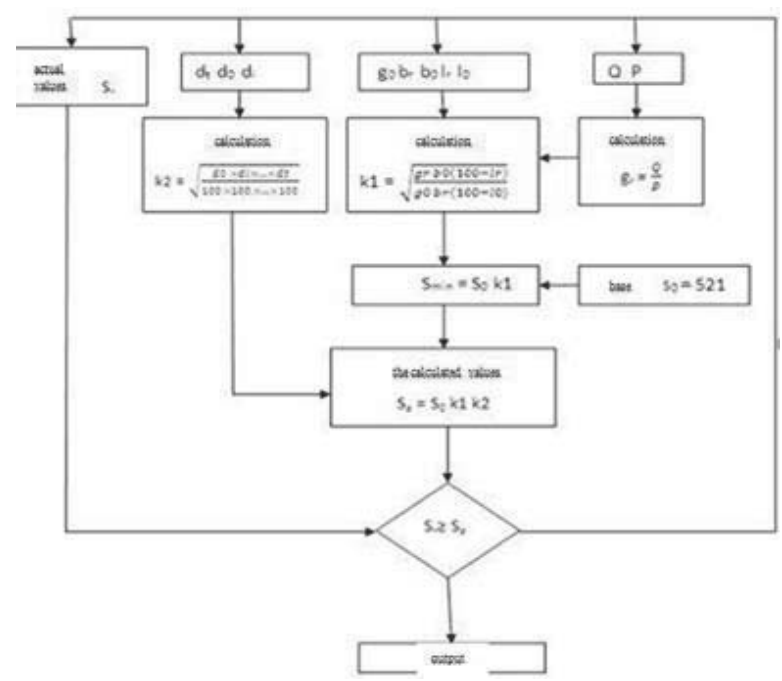

Figure 8. The algorithm for calculating the area of availability of commercial facilities in Samara.

Data required for the calculation are presented in Table 1. The additional criteria: the size of the territory of Samara $541.98 \mathrm{sq}$. km., and a population density - 2.1618 thous. persons / sq km.

Table 1. The resident population (at the beginning of the year, thousand pers.)

\begin{tabular}{|l|c|c|c|c|c|}
\hline \multirow{2}{*}{ Areas of Samara } & \multicolumn{5}{|c|}{ Years } \\
\cline { 2 - 6 } & 2009 & 2010 & 2011 & 2012 & 2013 \\
\hline Samara & 1134,8 & 1133,8 & 1166,6 & 1169,3 & 1171,7 \\
\hline Samara & 1134,7 & 1133,7 & 1188,5 & 1169,2 & 1171,6 \\
\hline Zheleznodorozhny & 100,7 & 100,0 & 103.2 & 102,5 & 100,9 \\
\hline Kirovsky & 226,7 & 226,0 & 229,3 & 228,9 & 226,6 \\
\hline Krasnoglinsky & 82,8 & 82,4 & 85,6 & 85,0 & 85,6 \\
\hline Kuybyshevsky & 79,3 & 79,6 & 86,4 & 86,9 & 87,5 \\
\hline Leninsky & 62,7 & 62,4 & 65,6 & 65,3 & 65,1 \\
\hline Oktyabrsky & 107,8 & 107,9 & 114,5 & 115,5 & 118,2 \\
\hline Promyshlenny & 267,1 & 267,3 & 273,6 & 275,7 & 276,2 \\
\hline Samarsky & 30,1 & 30.1 & 30,6 & 30,6 & 30,7 \\
\hline Sovetsky & 177,5 & 178,0 & 177,7 & 179,4 & 180,7 \\
\hline The countryside & 0,1 & 0.1 & 0,1 & 0,1 & 0,1 \\
\hline
\end{tabular}

Based on the data presented in Table 1, was developed linear prediction model of population growth Samara.

$\mathrm{P}(\mathrm{t})=\mathrm{P} 0+\mathrm{at}$,

where $P(t)$ - population growth by year (thousand. pers.);

$\mathrm{PO}=1154$ thous. pers. - original population (as a starting point taken in 2009 year);

$a=2,55$ thous. pers./year - the rate of population growth.

Table 2. Retail trade turnover

\begin{tabular}{|l|c|c|c|c|c|}
\hline \multirow{2}{*}{ Title } & \multicolumn{5}{|c|}{ Years } \\
\cline { 2 - 6 } & 2008 & 2009 & 2010 & 2011 & 2012 \\
\hline Retail trade turnover per capita, rubles. & 152339 & 162516 & 172951 & 168339 & 179941 \\
\hline
\end{tabular}


Based on the data in Table 2 was developed linear mathematical model of retail trade turnover per capita by year.

$Q(t)=Q_{0}+\beta t$,

where $\mathrm{Q}(\mathrm{t})$ - linear mathematical model of retail trade turnover per capita by year (thous. rub. / pers.);

$Q_{0}=161$ thous. rub. / person. - Initial retail trade turnover (as a starting point taken in 2009 year);

$\beta=7$ thous. rub./person. year - the rate of change of retail trade turnover.

Table 3. Socio-economic indicators of living standards

\begin{tabular}{|l|c|c|c|c|c|}
\hline \multirow{2}{*}{ Title } & \multicolumn{5}{|c|}{ Years } \\
\cline { 2 - 6 } & 2008 & 2009 & 2010 & 2011 & 2012 \\
\hline Cost of living, руб. & 4984 & 5408 & 6191 & 6420 & 6906 \\
\hline Cреднемесячная зарплата, rubles. & 17615 & 18471 & 20690 & 23078 & 26148 \\
\hline Real wages,\% to previous year & 109 & 95 & 106 & 103 & 109 \\
\hline
\end{tabular}

Based on the data in Table 3 developed linear mathematical model of a living wage.

$\Pi(\mathrm{t})=\Pi_{0}+\mu t$,

where $\Pi(t)$ - linear mathematical model of retail trade turnover per capita by year (thous. rub. / pers.);

$\Pi_{0}=5,4$ thous. rub./person. - Initial retail trade turnover (as a starting point taken in 2009 year);

$\mu=0,5$ thous. rub./person. year - the rate of change of retail trade turnover.

Determining the number of minimum values of availability of the Samara area of retail properties is presented in equation (4)

$\mathrm{S}_{\min }=\mathrm{S}_{0} \mathrm{k} 1=\mathrm{S}_{\text {food }}+\mathrm{S}_{\text {nonfood }}$

where $S_{\min }$ - the minimum standard of security of the population area of retail properties;

$\mathrm{S}_{0}=521$ - a baseline minimum security of the population of the Russian Federation area retail properties (sq. $\mathrm{m}$. per 1 thousand people)

$\mathrm{k}_{1}$ - regional factor correction;

Sfood - the minimum standard of security of the population area of shopping facilities for the sale of food products Samara (sq. m. per 1 thousand people);

Snonfood - the minimum standard of security of the population area of shopping facilities for the sale of non-food goods Samara (sq. m. per 1 thousand people).

Recalculation of minimum standards for security of the population area of retail properties at the end of their validity period is made taking into account the changes in real incomes.

To recalculate the minimum standards for security of the population area retail properties using the formula (5).

$\mathrm{S}_{\mathrm{p}}=\mathrm{S}_{0} \mathrm{k}_{1} \mathrm{k}_{2}$

where $k_{2}$ - regional correction factor for the changes in real incomes.

For the current year t received the year preceding the year in which recalculate the minimum security standards for the population of the area of commercial properties.

$d_{0}$ - real disposable incomes of Samara in the base year (\% to previous year) according to the statistical bodies;

$d_{i}$ - real disposable incomes of Samara in the years following the base (\% to previous year) according to the statistical bodies (Table 4).

Table 4. The real disposable income of the population of Samara in the years following the base

\begin{tabular}{|l|c|c|c|c|c|}
\hline \multirow{2}{*}{ Title } & \multicolumn{5}{|c|}{ Years } \\
\cline { 2 - 6 } & 2008 & 2009 & 2010 & 2011 & 2012 \\
\hline Real wages,\% to previous year & 109 & 95 & 106 & 103 & 109 \\
\hline
\end{tabular}

Based on the data in Table 4 calculate k2 - Regional correction factor for the changes in the real incomes of the population (as the base year taken 2009).

The first recalculation minimum standards for security of the population area of retail properties in the base year was adopted in 2009, with subsequent recalculations - the year in which the minimum standards held recalculation of availability of area shopping facilities.

k2 $=1,06$

Calculations show that a correction factor of regional adjustment for changes in the real income of the population has the correction values in hundredths and further calculations has almost no effect. 


\section{References}

Trade development strategy in the Russian Federation for 2011 - 2015 years, and until 2020, approved by order of the Russian Industry and Trade Ministry on March 31, 2011 № 422

Pisareva E.V. Models of consumer preferences of retail trade enterprises in shaping the marketing system sales company in the modern economy // Economy Management, Economics, №12 (85), 2011

Electronic versions of publications // Official site of the territorial body of the Federal State Statistics Service of the Samara region

Government Decree of 24.09 .2010 № 754 «On approval of the establishment of minimum standards for security of the population area of shopping facilities // Meeting of the legislation of the Russian Federation, 04.10.2010, № 40, Art. 5081. 